\title{
Diversidad genética y resistencia a los antibióticos de Campylobacter jejuni aislado de pollos en Quito - Ecuador, noviembre 2017- septiembre 2018
}

\author{
Montero Toro, Lorena Patricia ${ }^{1,2^{\star}}$; Medina, Josée ${ }^{\star}$; Trueba Piedrahita, Gabriel ${ }^{1}$; Vinueza Burgos, Christian ${ }^{2}$ \\ ${ }^{1}$ Instituto de Microbiología de la Universidad San Francisco de Quito, Quito, Ecuador. \\ ${ }^{2}$ Unidad de Investigación de Enfermedades Transmitidas por Alimentos y Resistencia a los Antimicrobianos (UNIETAR) \\ de la Universidad Central del Ecuador, Quito, Ecuador. \\ e-mail: lpmonterot@gmail.com \\ lmonterot@estud.usfq.edu.ec
}

Palabras clave: Cadena alimenticia, Campylobacter jejuni, genotipo, resistencia a los antibióticos, transmisión.

INTRODUCCIÓN: Campylobacter jejuni ha sido reconocido como una causa importante de diarrea en todo el mundo. [1] Esta bacteria exhibe una alta frecuencia de variación genética asociada con cambios en los antígenos de la superficie celular. [2]

En varios países industrializados se ha informado un aumento en la resistencia a los antibióticos de C. jejuni, pero se conoce poco la epidemiología de la resistencia a los antibióticos de Campylobacter en los países en desarrollo. [3]

OBJETIVO: Determinar el perfil de susceptibilidad a la ciprofloxacina, tetraciclina y eritromicina y los genotipos de Campylobacter aislado de la industria avícola y humanos en Ecuador.

MATERIALES Y MÉTODOS: El estudio fue realizado entre noviembre de 2017 y septiembre de 2018 en la ciudad de Quito. Se recuperó 134 aislamientos de $C$. jejuni (44 aislamientos de granjas avícolas, 90 de pollo del comercio minorista y 3 aislados humanos) de los cuales se seleccionaron 37 aislamientos como un subconjunto representativo de esta colección. La diversidad genética de los aislados de $C$. jejuni fueron investigados mediante Multilocus sequence typing (MLST) y la resistencia a eritromicina, tetraciclina y ciprofloxacina se evaluó mediante difusión en disco.
RESULTADOS: Se obtuvieron 23 secuencias tipo (ST), los complejos clonales más frecuentemente observados fueron CC-354, CC-353 y CC-607. El ST1036 se encontró en aislados de muestras de origen humano y animal. Además, se encontró el ST-7669 en aislamientos de carcasas (minorista) y ciegos de pollo (granja) de diferentes áreas de las zonas de muestreo. Por el contrario, se aislaron cepas del ST-9336 de muestras recogidas de la misma área. Trece de los 34 aislamientos de los que se obtuvo su perfil de susceptibilidad eran resistentes a los tres antibióticos probados. La tasa de resistencia más alta fue a la ciprofloxacina $(70,6 \%)$, seguida de tetraciclina $(67,6 \%)$ y eritromicina $(35,3 \%)$.

CONCLUSIONES: Los resultados mostraron alta resistencia a la ciprofloxacina en $C$. jejuni. Se encontraron ST superpuestos entre aislamientos de granjas, carcasas de tiendas minoristas y humanos, lo que demuestra la posibilidad de transmisión de este patógeno en la cadena alimenticia. Otros estudios mostrarían la relevancia de $C$. jejuni en la epidemiología de la campilobacteriosis humana en Ecuador.

\section{REFERENCIAS:}

[1] European Food Safety Authority and European Centre for Disease Prevention and Control. The European Union summary report on trends and sources of zoonoses, zoonotic agents and foodborne outbreaks in 2017. EFSA J. 2018; 16(12).

[2] Young KT, Davis LM, DiRita VJ. Campylobacter 
jejuni: Molecular biology and pathogenesis. Nat Rev Microbiol. 2007; 5(9):665-679.

[3] Kaakoush NO, Castaño-Rodríguez N, Mitchell HM, Man SM. Global epidemiology of campylobacter infection. Clin Microbiol Rev. 2015; 28(3):687-720. 